\title{
MMMII Use of Accessible Examination Tables in the Primary Care Setting: A Survey of Physical Evaluations and Patient Attitudes
}

\author{
Megan A. Morris, PhD, MPH, CCC-SLP ${ }^{1,2,3}$, Allysha C. Maragh-Bass, PhD, MPH ${ }^{3}$, \\ Joan M. Griffin, $P h D^{1,2}$, Lila J. Finney Rutten, $P h D^{1,2}$, Tara Lagu, MD ${ }^{4,5,6}$, and Sean Phelan, $P h D^{2}$ \\ ${ }^{7}$ Mayo Clinic Robert D. and Patricia E. Kern Center for the Science of Health Care Delivery, Rochester, MN, USA; ${ }^{2}$ Department of Health Sciences \\ Research, Mayo Clinic, Rochester, MN, USA; ${ }^{3}$ Center for Surgery and Public Health, Brigham and Women's Hospital, Boston, MA, USA; ${ }^{4}$ Center for \\ Quality of Care Research, Baystate Medical Center, Springfield, MA, USA; 5 Department of Medicine, Tufts University School of Medicine, Boston, \\ MA, USA; ${ }^{6}$ Division of Hospital Medicine, Baystate Medical Center, Springfield, MA, USA.
}

BACKGROUND: Accessible diagnostic equipment, including height-adjustable examination tables, is necessary to accommodate patients with disabilities. Studies demonstrate that only a minority of clinics provide accessible equipment. For clinics with this equipment, no studies have examined the use of such equipment in routine clinical care.

OBJECTIVE: In primary care clinics with and without height-adjustable examination tables, we compared the frequency and variation in physical evaluations on examination tables and patients' perceptions of quality care.

DESIGN: Survey administered to patients at two primary care clinics in Rochester, MN, in 2015. One clinic had height-adjustable examination tables in every exam room; the other clinic had none.

PATIENTS: A total of 399 English-speaking adult primary care patients (61\% participation).

MAIN MEASURES: Participants were asked whether they were physically evaluated on a table during their clinical encounter. In addition, they completed two subscales of the Patient Perception of Quality of Care survey: Perceptions of Provider's Bedside Manner and Perceptions of Provider's Work.

KEY RESULTS: Overall, there were no differences between clinics in the likelihood of patients being examined on an exam table or in their perceptions of quality of care. Across both clinics, patients who reported a disability were $27 \%$ less likely to be examined on a table, were less likely to rate their provider's bedside manner favorably (74\% vs. 59\%) and to have positive perceptions of their provider's work (46\% vs. 32\%) than patients without disabilities.

CONCLUSIONS: The presence of accessible medical equipment was not associated with care delivered to patients. While this might not be meaningful for most patients, it could be problematic for patients with disabilities, who are less likely to be examined. Therefore, accessible equipment alone may not be sufficient to reduce disparities in the care experience. Provider- and organization-level factors must thus be considered in efforts to provide equitable care to patients with disabilities.

KEY WORDS: disability; primary care; access to care; disparity.

Received October 21, 2016

Revised March 2, 2017

Accepted August 2, 2017

Published online September 18, 2017
J Gen Intern Med 32(12):1342-8

DOI: $10.1007 / \mathrm{s} 11606-017-4155-2$

(c) Society of General Internal Medicine 2017

\section{INTRODUCTION}

According to the Americans with Disabilities Act (ADA) and Section 504 of the Rehabilitation Act of 1973, healthcare organizations must ensure equal access to healthcare services and facilities for patients with disabilities, including reasonable modifications when necessary. ${ }^{1,2}$ Despite this legislation, multiple studies have found that patients with mobility impairments receive less preventive care and fewer examinations than patients without disabilities. This disparity has been attributed, in part, to inaccessible medical environments. ${ }^{3-17}$ The Department of Justice (DoJ), which is charged with enforcing the ADA (under Title II for public entities and Title III for public accommodations), recommends that when patients with lower-limb mobility impairments undergo physical exams or procedures on a table, either a height-adjustable examination table or mechanical lift should be used. ${ }^{1}$

Despite the DoJ recommendation, recent studies have found that outpatient healthcare clinics often do not have accessible equipment available. In a study of 2389 primary care clinics, only $8.4 \%$ reported the availability of a height-adjustable examination table. ${ }^{18}$ Additionally, a study of 256 specialty outpatient clinics found that only $9 \%$ of clinics reported using a height-adjustable or mechanical lift for transferring patients with mobility disabilities. ${ }^{19}$ Notably, these studies quantified the presence, not the use, of height-adjustable tables and mechanical lifts. In clinics with height-adjustable examination tables, it is not known when and how healthcare providers use the tables, whether accessible medical equipment affects care processes for patients with or without disabilities, or whether patients' perceptions of healthcare quality are associated with whether they were evaluated on an exam table.

Accessible equipment may also benefit other patient populations. For example, height-adjustable examination tables could benefit obese or frail patients who have difficulty stepping onto a narrow examination table step. A universally designed clinic in which all examination tables are height- 
adjustable might have broad benefits. Unfortunately, such tables can cost thousands of dollars more than static examination tables. Healthcare clinics must therefore determine whether the clinical benefits of height-adjustable tables are worth the additional cost. However, there are currently no data on whether the presence of height-adjustable examination tables affects clinical care for either disabled or non-disabled patients. Likewise, although policies point to the importance of adjustable equipment in providing high-quality care for patients with disabilities, it is not clear whether having adjustable tables correlates with patients' perceptions of quality healthcare.

Therefore, to better understand the use of accessible equipment in healthcare settings, we aimed to (1) explore the likelihood of physical examinations occurring on tables when height-adjustable physical examination tables were and were not available, and whether this varied by disability status or other personal factors; and to (2) explore the association between perceived quality of care and evaluation on an examination table.

\section{METHODS}

Setting and Participants. We conducted the study at two comparable community-based primary care clinics at the Mayo Clinic in Rochester, MN, USA. One clinic (Clinic A) was established in the community and had 31 examination rooms, none of which had a height-adjustable examination table available. The other (Clinic B) opened in January of 2015 , and all of its 29 examination tables were height-adjustable. We surveyed a sample of adult patients at each clinic. The Mayo Clinic Institutional Review Board approved the study procedures.

Data Collection. We collected data approximately once a week between May and November 2015. Data collection was varied by day of the week and time of day. Study team members approached all patients in the clinic waiting rooms following their appointments. Criteria for participation included (a) age 18 or older, (b) ability to read or speak English as determined by self-report, and (c) ability to consent to participation.

\section{Measures}

Evaluation on Examination Table. The primary variable of interest was whether the patient was evaluated on an examination table. We asked participants whether they were physically evaluated during their appointments (yes/no), and if so, where the evaluation occurred (e.g., on the examination table, in a chair).

Patient Perceptions of Quality of Care. To assess patients' perceptions of care quality, we used two subscales of the validated Patient Perceptions of Quality of Care survey. ${ }^{20}$ Subscale 1, Patients' Perceptions of Provider's Bedside Manner, consisted of five items, and subscale 2, Patients' Perceptions of Provider's Work, comprised nine items. Each item in both subscales was rated on a five-point Likert scale ranging from "strongly agree" to "strongly disagree."

Demographic Questions. Participants completed demographic questions that included age, sex, race/ethnicity, height, weight, and disability status. We assessed disability status through eight questions that inquired about gross and fine motor, visual, hearing, speech and language, learning, and cognitive disabilities, as well as a general "yes/no" question about whether the patient had a disability.

\section{Analyses}

We first created a disability status variable $(0=$ no disability reported vs. 1 = any type of reported disability), established four age categories, and used height and weight to create BMI categories based on the Centers for Disease Control and Prevention (CDC)-defined classifications. ${ }^{21}$ Due to the sample size, in the adjusted models we collapsed obesity status and race/ethnicity each into two variables, (not obese vs. obese/ extremely obese; white vs. black/Hispanic/Asian/other). For all analyses, we collapsed responses to "evaluated on table" versus "not evaluated on table" (where $0=$ not evaluated at all/ not evaluated on the table vs. 1 = evaluated on the table). We grouped patients who were not physically evaluated with patients who were not evaluated on the examination table, as the purpose of the study was to measure the likelihood that patients were examined on the table, which we considered the "gold standard."

We conducted principal component analyses on both subscales of the Patient Perceptions of Quality of Care survey to assess the factor structure and internal reliability of the items. ${ }^{22}$ For the Patients' Perceptions of Provider's Bedside Manner subscale, all five items were retained with a one-factor solution, with excellent internal reliability (Cronbach's $\alpha=0.98)$. Similarly, for the Patients' Perceptions of Provider's Work subscale, we retained all nine items with a one-factor solution, with excellent internal reliability (Cronbach's $\alpha=0.98$ ).

For the adjusted analyses, we summed all items across each subscale. The summed scales were then dichotomized at the median to designate "high" and "low" responses. We then generated univariate frequencies for the dependent and independent variables on the total sample $(N=399)$ and by clinic (Clinic A/Clinic B).

For the outcomes in Aim 1 (evaluation on a table) and Aim 2 (patients' perception of care), we calculated bivariate (chisquare) statistics and unadjusted incidence rate ratios. We entered variables marginally significant $(p<0.10)$ into a multivariate Poisson regression model. Poisson regression is 
Table 1 Patient Demographic Characteristics by Clinic

\begin{tabular}{|c|c|c|c|}
\hline & $\begin{array}{l}\text { Clinic A }(N=200) \\
\text { No. }(\%)\end{array}$ & $\begin{array}{l}\text { Clinic B }(N=199)^{*} \\
\text { No. }(\%)\end{array}$ & $\overline{p \text {-value }}$ \\
\hline Sex & & & 0.94 \\
\hline Male & $60(30.0)$ & $59(29.7)$ & \\
\hline Female & $140(70.0)$ & $140(70.4)$ & \\
\hline Age (in years) & & & 0.28 \\
\hline $18-34$ & $41(20.7)$ & $58(29.2)$ & \\
\hline $35-49$ & $51(25.8)$ & $46(23.1)$ & \\
\hline $50-64$ & $59(29.9)$ & $54(27.1)$ & \\
\hline$\geq 65$ & $47(23.7)$ & $41(20.6)$ & \\
\hline Race & & & 0.02 \\
\hline White (non-Hispanic) & $184(92.0)$ & $193(97.5)$ & \\
\hline Non-white or Hispanic ${ }^{\dagger}$ & $16(8.0)$ & $5(2.5)$ & \\
\hline BMI category & & & 0.75 \\
\hline Not obese $(\leq 29.9)$ & $114(60.3)$ & $124(62.9)$ & \\
\hline Obese $(\mathrm{BMI} \geq 30)$ & $75(39.7)$ & $71(36.1)$ & \\
\hline Disability status & & & 0.40 \\
\hline No disability & $155(77.5)$ & $161(80.9)$ & \\
\hline Any form of disability & $45(22.5)$ & $38(19.1)$ & \\
\hline $\begin{array}{l}\text { Evaluated on examination } \\
\text { table }\end{array}$ & & & 0.97 \\
\hline Not examined on table & $74(37.2)$ & $72(36.7)$ & \\
\hline Examined on table & $125(62.8)$ & $124(63.3)$ & \\
\hline $\begin{array}{l}\text { Provider's bedside } \\
\text { manner }\end{array}$ & & & 0.56 \\
\hline High ratings & $61(30.8)$ & $56(28.1)$ & \\
\hline Low ratings & $137(69.2)$ & $143(71.9)$ & \\
\hline $\begin{array}{l}\text { Perceptions of provider's } \\
\text { work }^{*}\end{array}$ & & & 0.57 \\
\hline High ratings & $110(55.8)$ & $115(58.7)$ & \\
\hline Low ratings & $87(44.2)$ & $81(41.3)$ & \\
\hline
\end{tabular}

*All examination tables in the clinic were height-adjustable

†Due to small numbers, we collapsed the patients reporting as black (non-Hispanic), Asian, Hispanic, and other

$\neq$ Determined by the Patient Perception of Quality Scale. For unadjusted and adjusted analyses, scale items were summed and then dichotomized at the median

appropriate for binary outcomes which are common (greater than $10 \%$ prevalence). ${ }^{23}$ We used robust standard errors to account for non-constant variance in the data. ${ }^{24}$ We retained sex, race, obesity status, and site of clinic visit as control variables in the final model, despite non-significance. We conducted analyses on complete cases only, due to acceptable missingness $(<10 \%){ }^{23}$ The final model yielded acceptable Hosmer-Lemeshow goodness-of-fit statistics (chi-square $=139.1 ; p>0.05) .{ }^{25}$ We considered values of $<0.05$ as statistically significant. We conducted all analyses in STATA version 14.0 software. $^{26}$

\section{RESULTS}

A total of 399 participants (200 in Clinic A and 199 in Clinic B) completed the survey. The response rate for participation was $61 \%$, with lack of time the most common reason for refusal. The completion rate for the various survey items ranged from 95 to $100 \%$. Across the two clinics, the respondents were $70 \%$ female and $95 \%$ white (non-Hispanic), with $38 \%$ reporting being obese and $21 \%$ reporting a disability (Table 1). Patient age ranged from 18 to 88 years, with the ages evenly distributed across four age categories (18-34: 23\%; 35-49: 26\%; 50-64: 29\%; $\geq 65: 22 \%)$. We observed no demographic differences between the two clinics, although more patients reported a race/ethnicity other than white in Clinic A than in Clinic B (8\% versus $2.5 \%$, $p<0.05)$.

\section{Aim 1: Evaluation on Examination Table}

In our sample, 149 (75\%) patients in Clinic A and $146(73 \%)$ patients in Clinic B reported being physically evaluated. Of those evaluated, 249 (84\%) were evaluated on an examination table, and 46 (16\%) were evaluated sitting in a chair, on a bench, or standing up.

In unadjusted Poisson regression models, there was no difference in the likelihood of being evaluated on the table by clinic site. Likewise, there was no difference in the likelihood of being examined on the table by sex, race/ethnicity, or obesity. We did find differences, however, by age and disability status across clinics (Table 2). In the unadjusted model, patients aged 65 and older were $20 \%$ less likely to be evaluated on a table than patients 18-34 years of age $(p<0.05)$. Adjusting for sex, race, obesity status, and site of clinic visit, patients aged 50-64 years were 18\% less likely to be evaluated on the table than patients 18-34 years $(p<0.05)$. In the unadjusted model, compared to patients without disabilities, patients with disabilities were $27 \%$ less likely to be evaluated on the table $(p<0.001)$. In both unadjusted and adjusted analyses of patients with disabilities, we found no statistically significant difference between clinics in the proportion of patients examined on the table $(p=0.38, p=0.73)$. 
Table 2 Correlates of Evaluation on an Examination Table $(N=378)$

\begin{tabular}{|c|c|c|c|c|}
\hline & \multicolumn{2}{|c|}{ Unadjusted } & \multicolumn{2}{|c|}{ Adjusted } \\
\hline & IRR & CI & AIR & CI \\
\hline \multicolumn{5}{|l|}{ Clinic } \\
\hline Clinic B (accessible tables) & 0.99 & $(0.86,1.16)$ & 0.95 & $(0.82,1.10)$ \\
\hline Ref: Clinic A (no accessible tables) & 1.00 & & 1.00 & \\
\hline \multicolumn{5}{|l|}{ Sex } \\
\hline Female & 1.07 & $(0.90,1.27)$ & 1.04 & $(0.88,1.23)$ \\
\hline Ref: Male & 1.00 & & 1.00 & \\
\hline \multicolumn{5}{|l|}{ Age (in years) } \\
\hline $35-49$ & 0.87 & $(0.72,1.07)$ & 0.91 & $(0.74,1.12)$ \\
\hline $50-64$ & 0.86 & $(0.71,1.05)$ & $0.83 *$ & $(0.68,0.99)$ \\
\hline$\geq 65$ & $0.80 *$ & $(0.64,1.00)$ & 0.96 & $(0.78,1.18)$ \\
\hline Ref: 18-34 & 1.00 & & 1.00 & \\
\hline \multicolumn{5}{|l|}{ Race } \\
\hline Black/Hispanic/Asian/Other & 0.83 & $(0.55,1.26)$ & 0.97 & $(0.66,1.43)$ \\
\hline Ref: White & 1.00 & & 1.00 & \\
\hline \multicolumn{5}{|l|}{ Obesity status } \\
\hline Obese $\mathrm{BMI} \geq 30$ & 1.10 & $(0.94,1.28)$ & 1.10 & $(0.95,1.27)$ \\
\hline Ref: Non-obese BMI $\leq 29.9$ & 1.00 & & 1.00 & \\
\hline \multicolumn{5}{|l|}{ Disability status } \\
\hline Any form of disability & $0.73 * *$ & $(0.57,0.92)$ & 0.78 & $(0.61,1.00)$ \\
\hline Ref: No disability & 1.00 & & 1.00 & \\
\hline
\end{tabular}

$* p<0.05, * *_{p}<0.01$

$I R R=$ incidence rate ratio, $A I R=$ adjusted incidence rate ratio, $C I=95 \%$ confidence interval

\section{Aim 2: Patients' Perceptions of Their Providers}

In both unadjusted and adjusted analyses, there were no differences by clinic in patients' ratings of their provider's bedside manner $(p=0.56, p=0.69)$ or of their provider's work $(p=0.57, p=0.39)$. Similarly, in adjusted sub-analyses of only patients with disabilities, no differences by clinic were observed in patients' ratings in either subscale $(p=0.73, p=0.81)$. We then compared the ratings by patients who were and were not evaluated on an examination table, which revealed significantly higher ratings among patients who were evaluated on an examination table for both their provider's bedside manner $(p<0.001)$ and perceptions of their provider's work $(p<0.001)$. We did find differences in perceptions by disability status. Compared to patients without disabilities, patients with disabilities in both clinics were less likely to have favorable ratings of their provider's bedside manner $(74 \%$ vs. $59 \% ; p<0.01)$ and less likely to have positive perceptions of their provider's work ( $46 \%$ vs. $32 \% ; p<0.05$ ). (See Appendix Tables 3 and 4 for a comparison of the items between patients with and without disabilities.)

\section{DISCUSSION}

In this study we found that over $60 \%$ of primary care patients were evaluated on examination tables during their clinical encounters, and that this proportion did not differ between clinics with and without height-adjustable examination tables. Additionally, there was no difference between clinics in the proportion of patients with disabilities who were examined, although our sample size was small. This suggests that the availability of height-adjustable examination tables was not associated with a difference in the delivery of care to patients with versus without disabilities.

We did find differences, however, in the likelihood of being examined on a table by both age and disability status. In unadjusted models, older patients and patients with disabilities were less likely to be examined on a table than younger or non-disabled patients. These findings are consistent with previous studies demonstrating that patients with disabilities are less likely to receive physical examinations than patients without disabilities. ${ }^{3,5,12-14,16,17}$ In addition, those who were not evaluated on a table had less favorable perceptions of their care.

The lack of a difference between clinics in the likelihood of examination does not imply that height-adjustable tables provide no benefit in caring for patients with or without disabilities. Moreover, merely installing these tables may not be sufficient to prompt changes in providers' established physical examination routines or patients' perceptions of the quality of their healthcare. It is possible that greater education and exposure may encourage more frequent use of height-adjustable tables among providers for patients both with and without disabilities, which may in turn improve patients' perceptions of care. Further research is needed to determine whether additional education or supports may increase this practice, and whether it is associated with improved patient satisfaction or clinical benefit. 
We found that provider ratings were lower among patients with disabilities than those without disabilities. This is consistent with previous studies in which quality-of-care ratings were lower for patients with disabilities than for non-disabled patients. ${ }^{27,28}$ It is unclear in our study whether the differences in patient experience were related to the reduced likelihood of physical exam. We did find across all patients that lower provider ratings were associated with a lower likelihood of being examined on a table, and that examination on a table was less likely in patients with disabilities. Therefore, it is plausible that the decreased likelihood of physical examination contributed to the lower provider ratings by disabled patients. This hypothesis is supported by existing literature demonstrating that patient perceptions of the thoroughness of their evaluation and of the provider's technical skills are associated with higher satisfaction with their primary care providers. ${ }^{29-31}$

Prior studies indicate that accessible equipment in practices is rare. ${ }^{18,19}$ Policy reform has thus been aimed at increasing the presence of accessible equipment in healthcare settings. ${ }^{1,32}$ Section 4203 of the Patient Protection and Affordable Care Act (ACA) reinforced the requirement for accessible diagnostic equipment within healthcare organizations by mandating the creation of a US Access Board committee to develop guidelines for accessible medical equipment. ${ }^{32,33}$ Our findings suggest that disparities persist even in the presence of accessible equipment; thus these policy efforts, while necessary, will likely fall short of reducing disparities in care for patients with disabilities. To ensure equitable care for these patients, a broader look at the entire healthcare setting is needed, particularly regarding providers' approaches towards caring for patients with disabilities.

There are several reasons why a provider might not physically examine a patient with a disability. First, providers' attitudes and assumptions about these patients could influence how they provide care. For example, women with disabilities report that providers assume that they are "asexual," and are surprised when patients inquire about contraception or express a desire to bear children. ${ }^{34,35}$ Such attitudes may contribute to the lower prevalence of pap smears in women with mobility impairments. $5,16,17$ Second, even if the table is accessible, transferring patients with mobility impairments or other disabilities onto an examination table could take longer than having them remain in a chair. In time-constrained visits, for the sake of efficiency, providers may decide not to transfer the patient onto a table. Finally, providers may not have the training or available resources to transfer patients with disabilities onto exam tables or to perform appropriate, thorough physical examinations. Unfortunately, no evidence-based training or other resources exist to assist providers in caring for patients with disabilities.

While there are no rules regarding the number of accessible examination tables required per clinic, some recommend that at least one table be made available per department. ${ }^{13}$ In the current study, Clinic B had heightadjustable examination tables available in all of the examination rooms. While it might seem more economical for clinics to purchase only one heightadjustable examination table, they should keep in mind that this could add a significant work burden. Patients requiring such a table would either need to be previously scheduled or transferred to the room with the table, likely increasingly the length of the clinical encounter considerably. This underscores the need to evaluate not only the cost of the equipment but also the time and resources necessary to ensure equitable access to care for patients with disabilities.

Due to our small sample size, we collapsed all disability categories and did not examine differences in the likelihood of being evaluated on the table across disability types. While patients with physical disabilities and those who are nonambulatory are more likely to require height-adjustable examination tables, it is conceivable that other disability patient populations, such as those with visual impairments, could also benefit from height-adjustable tables. It is also possible that our study masked differences within the disability categories, and that patients with certain types of disabilities might be experiencing an even greater disparity in the likelihood of physical examination compared to non-disabled patients. In a recent study by Horner-Johnson et al. (2014), patients across multiple disability categories (physical, visual, cognitive, hearing, and multiple disabilities) had varying rates of receiving preventive care services. ${ }^{36}$ Further studies are encouraged to determine whether there are differences in the likelihood of examination by disability type, as this will help direct future interventions aimed at improving the quality of care for patients with disabilities. Additionally, we excluded participants who were unable to consent to participate, which could have resulted in an underrepresentation of the patients with disabilities in our sample.

\section{CONCLUSIONS}

This study is the first to explore the association between physical evaluation on a table and the availability of height-adjustable examination tables in the primary care setting. The results demonstrate that the presence of height-adjustable examination tables may not affect care delivery. While this might not have an effect on most patients, it could be detrimental to patients with disabilities, who were less likely to be examined. Therefore, the mere availability of accessible examination tables does not ensure that patients with disabilities receive "equal access to healthcare services." In order to provide high-quality, patient-centered care, providers and administrators need to consider all factors, including the physical environment, clinical processes and policies, and provider-level characteristics, that may affect the quality of care. 
Acknowledgements: The authors would like to thank Ashley Pitzer, who assisted with survey collection, and Avni Gupta, for her assistance in analyzing the data. This research was supported by the Mayo Clinic Robert D. and Patricia E. Kern Center for the Science of Healthcare Delivery. The funder had no role in the design or conduct of the study, the analysis or interpretation of the data, or the review or approval of the manuscript. The results were presented at the 2016 American Public Health Association Annual Meeting and Expo in Denver, CO.

Corresponding Author: Megan A. Morris, PhD, MPH, CCC-SLP; Department of Health Sciences Research, Mayo Clinic, Rochester, MN, USA (e-mail: Megan.a.morris@ucdenver.edu).

\section{Compliance with Ethical Standards:}

Conflict of Interest: The authors declare that they have no conflict of interest.

\section{REFERENCES}

1. U.S. Department of Justice. Americans with Disabilities Act: Access to Medical Care for Individuals with Mobility Disabilities [cited 2016 June 30]. Available from: https://www.ada.gov/medcare_mobility_ta/ medcare_ta.htm\#part1. Accessed 30 June 2016.

2. Institute of Medicine (IOM). The Future of Disability in America. Washington, DC: National Academies Press; 2007:165-175.

3. Iezzoni LI. Eliminating health and health care disparities among the growing population of people with disabilities. Health Aff 2011;30(10):1947-54. doi: 10.1377/hlthaff.2011.0613.

4. Iezzoni LI, Kilbridge K, Park ER. Physical access barriers to care for diagnosis and treatment of breast cancer among women with mobility impairments. Oncol Nurs Forum 2010;37(6):711-7. doi: 10.1188/10.onf 711-717.

5. Iezzoni LI, McCarthy EP, Davis RB, Siebens H. Mobility impairments and use of screening and preventive services. Am J Public Health 2000;90(6):955-61.

6. Iezzoni LI, Park ER, Kilbridge KL. Implications of mobility impairment on the diagnosis and treatment of breast cancer. J Women's Health 2011;20(1):45-52. doi: 10.1089/jwh.2009.1831.

7. Reichard A, Stolzle H, Fox MH. Health disparities among adults with physical disabilities or cognitive limitations compared to individuals with no disabilities in the United States. Disabil Health J 2011;4(2):59-67. doi: 10.1016/j.dhjo.2010.05.003.

8. Pharr J, Chino M. Predicting barriers to primary care for patients with disabilities: a mixed methods study of practice administrators. Disabil Health J 2013;6(2):116-23. doi: 10.1016/j.dhjo.2012.11.003.

9. Smith DL. Disparities in health care access for women with disabilities in the United States from the 2006 National Health Interview Survey. Disabil Health J 2008;1(2):79-88. doi 10.1016/j.dhjo.2008.01.001.

10. Lee JC, Hasnain-Wynia R, Lau DT. Delay in seeing a doctor due to cost: disparity between older adults with and without disabilities in the United States. Health Serv Res 2012;47(2):698-720. doi: 10.1111/j.1475-6773. 2011.01346.x.

11. McCarthy EP, Ngo LH, Roetzheim RG, Chirikos TN, Li D, Drews RE, et al. Disparities in breast cancer treatment and survival for women with disabilities. Ann Intern Med 2006;145(9):637-45.

12. Lagu T, Iezzoni LI, Lindenauer PK. The axes of access-improving care for patients with disabilities. N Engl J Med 2014;370(19):1847-51. doi: 10.1056/NEJMsb 1315940

13. Kirschner KL, Breslin ML, Iezzoni LI. Structural impairments that limit access to health care for patients with disabilities. JAMA 2007;297(10):1121-5. doi: 10.1001/jama.297.10.1121.

14. Iezzoni LI, Kurtz SG, Rao SR. Trends in mammography over time for women with and without chronic disability. Journal of Women's Health. 2015; 24(7):593-601. doi: 10.1089/jwh.2014.5181.

15. Iezzoni LI, Wint AJ, Smeltzer SC, Ecker JL. Physical Accessibility of Routine Prenatal Care for Women with Mobility Disability. Journal of Women's Health. 2015;24(12):1006-12. doi: 10.1089/jwh.2015.5385
16. Wisdom JP, McGee MG, Horner-Johnson W, Michael YL, Adams E, Berlin M. Health disparities between women with and without disabilities: a review of the research. Soc Work Public Health 2010;25(3):368-86. doi: 10.1080/19371910903240969.

17. Chevarley FM, Thierry JM, Gill CJ, Ryerson AB, Nosek MA. Health, preventive health care, and health care access among women with disabilities in the 1994-1995 National Health Interview Survey, Supplement on Disability. Womens Health Issues. 2006;16(6):297-312. doi: 10. 1016/j.whi.2006.10.002

18. Mudrick NR, Breslin ML, Liang M, Yee S. Physical accessibility in primary health care settings: results from California on-site reviews. Disabil Health J 2012;5(3): 159-67. doi: 10.1016/j.dhjo.2012.02.002.

19. Lagu T, Hannon NS, Rothberg MB, Wells AS, Green KL, Windom MO, et al. Access to subspecialty care for patients with mobility impairment: a survey. Ann Intern Med 2013;158(6):441-6. doi: 10.7326/0003-4819158-6-201303190-00003.

20. Haddad S, Potvin L, Roberge D, Pineault RR, M. Patient perception of quality following a visit to a doctor in a primary care unit. Fam Pract 2000;17:21-9

21. Center for Disease Control and Prevention. Defining Adult Overweight and Obesity Atlanta, GA2016 [cited 2016 August 26th]. Available from: https://www.cdc.gov/obesity/adult/defining.html.

22. Hotelling $\mathbf{H}$. Analysis of a complex of statistical variables into principal components. J Educ Psychol 1933;24:417-520.

23. Bennett DA. How can I deal with missing data in my study? Aust $\mathrm{N} Z \mathrm{~J}$ Public Health 2001;25(5):464-9.

24. Dean CL, J.F. Tests for Detecting Overdispersion in Poisson Regression Models. J Am Stat Assoc 1989;84(406):467-72.

25. Hosmer DW, Lemeshow S. Applied Logistic Regression. 2nd ed. Hoboken, NJ: Wiley; 2005.

26. StatCorp. Stata Statistical Software for Windows. 14.0 ed. College Station, TX: StataCorp; 2015.

27. Hoffman JM, Yorkston KM, Shumway-Cook A, Ciol MA, Dudgeon BJ, Chan L. Effect of communication disability on satisfaction with health care: a survey of medicare beneficiaries. Am J Speech Lang Pathol 2005;14(3):221-8. doi: 10.1044/1058-0360(2005/022).

28. Iezzoni LI, Davis RB, Soukup J, O'Day B. Satisfaction with quality and access to health care among people with disabling conditions. Int $\mathrm{J}$ Qual Health Care 2002;14(5):369-81.

29. Ali NS, Khuwaja AK, Kausar S, Nanji K. Patients' evaluations of family practice care and attributes of a good family physician. Qual Prim Care 2012;20(5):375-83.

30. Fung CH, Elliott MN, Hays RD, Kahn KL, Kanouse DE, McGlynn EA et al. Patients' preferences for technical versus interpersonal quality when selecting a primary care physician. Health Serv Res 2005;40(4):957-77. doi: 10.1111/j.1475-6773.2005.00395.x.

31. Kravitz RL, Cope DW, Bhrany V, Leake B. Internal medicine patients' expectations for care during office visits. J Gen Intern Med 1994;9(2):75-81.

32. Patient Protection and Affordable Care Act. Sect. 4203. Removing Barriers and Improving Access to Wellness for Individuals with Disabilities (2010).

33. Medical Diagnostic Equipment Accessibility Standards Advisory Committee. Advancing Equal Access to Diagnostic Services: Recommendations on Standards for the Design of Medical Diagnostic Equipment for Adults with Disabilities 2013 [cited 2016 July 5]. Available from: https://www. access-board.gov/guidelines-and-standards/health-care/about-thisrulemaking/advisory-committee-final-report.

34. Mitra M, Long-Bellil LM, Iezzoni LI, Smeltzer SC, Smith LD. Pregnancy among women with physical disabilities: Unmet needs and recommendations on navigating pregnancy. Disabil Health J 2016;9(3):457-63. doi: 10.1016/j.dhjo.2015.12.007.

35. Becker H, Stuifbergen A, Tinkle M. Reproductive health care experiences of women with physical disabilities: a qualitative study. Arch Phys Med Rehabil 1997;78(12 Suppl 5):S26-33.

36. Horner-Johnson W, Dobbertin K, Lee JC, Andresen EM. Disparities in health care access and receipt of preventive services by disability type: analysis of the medical expenditure panel survey. Health Serv Res 2014;49(6):1980-99. doi: 10.1111/1475-6773.12195. 


\section{APPENDIX}

Table 3 Patients' Perceptions of Provider's Bedside Manner by Disability Status

\begin{tabular}{|c|c|c|c|}
\hline & $\begin{array}{l}\text { No disability }(n=314) \\
\text { No. }(\%)\end{array}$ & $\begin{array}{l}\text { Any disability }(n=83) \\
\text { No. }(\%)\end{array}$ & $\overline{p \text {-value }}$ \\
\hline My provider was polite. & & & 0.01 \\
\hline Strongly disagree/Disagree & $19(6.1)$ & $6(7.2)$ & \\
\hline Neither/No opinion & $10(3.2)$ & $8(10.8)$ & \\
\hline Strongly agree/Agree & $285(90.7)$ & $68(81.9)$ & \\
\hline My provider respected me. & & & 0.04 \\
\hline Strongly disagree/Disagree & $19(6.1)$ & $6(7.2)$ & \\
\hline Neither/No opinion & $10(3.2)$ & $8(9.6)$ & \\
\hline Strongly agree/Agree & $285(90.8)$ & $69(83.1)$ & \\
\hline My provider had a reassuring attitude. & & & 0.06 \\
\hline Strongly disagree/Disagree & $19(6.1)$ & $6(7.2)$ & \\
\hline Neither/No opinion & $11(3.5)$ & $7(9.6)$ & \\
\hline Strongly agree/Agree & $284(90.4)$ & $69(83.1)$ & \\
\hline My provider respected my privacy during the physical examination. & & & 0.20 \\
\hline Strongly disagree/Disagree & $18(5.7)$ & $5(6.0)$ & \\
\hline Neither/No opinion & $34(10.8)$ & $15(18.1)$ & \\
\hline Strongly agree/Agree & $262(83.4)$ & $63(75.9)$ & \\
\hline $\begin{array}{l}\text { My provider expressed interest in me by listening and encouraging } \\
\text { me to express my problems. }\end{array}$ & & & 0.14 \\
\hline Strongly disagree/Disagree & $19(6.1)$ & $5(6.0)$ & \\
\hline Neither/No opinion & $13(4.1)$ & $7(9.6)$ & \\
\hline Strongly agree/Agree & $282(89.8)$ & $61(84.3)$ & \\
\hline
\end{tabular}

Table 4 Patients' Perceptions of Provider's Work by Disability Status

\begin{tabular}{|c|c|c|c|}
\hline & $\begin{array}{l}\text { No disability } \\
(n=314)\end{array}$ & $\begin{array}{l}\text { Any disability } \\
(n=83)\end{array}$ & $\overline{p \text {-value }}$ \\
\hline My health problems were explained to me clearly and completely. & & & 0.01 \\
\hline Strongly disagree/Disagree & $19(6.1)$ & $5(6.0)$ & \\
\hline Neither/No opinion & $21(6.7)$ & $14(16.9)$ & \\
\hline Strongly agree/Agree & $274(87.3)$ & $64(77.1)$ & \\
\hline The tests were explained to me clearly and completely. & & & 0.30 \\
\hline Strongly disagree/Disagree & $18(5.7)$ & $6(7.2)$ & \\
\hline Neither/No opinion & $48(15.3)$ & $18(21.7)$ & \\
\hline Strongly agree/Agree & $248(79.0)$ & $59(71.1)$ & \\
\hline My treatment options were explained to me clearly and completely. & & & 0.03 \\
\hline Strongly disagree/Disagree & $19(6.1)$ & $5(6.0)$ & \\
\hline Neither/No opinion & $23(7.3)$ & $14(16.9)$ & \\
\hline Strongly agree/Agree & $272(86.6)$ & $64(77.1)$ & \\
\hline I was comfortable with my involvement in the decisions about the & & & 0.01 \\
\hline tests and treatments. & & & \\
\hline Strongly disagree/Disagree & $19(6.0)$ & $5(6.0)$ & \\
\hline Neither/No opinion & $16(5.1)$ & $12(14.5)$ & \\
\hline Strongly agree/Agree & $279(88.9)$ & $66(79.5)$ & \\
\hline Time spent with my provider was the right amount. & & & 0.02 \\
\hline Strongly disagree/Disagree & $20(6.4)$ & $5(6.1)$ & \\
\hline Neither/No opinion & $11(3.5)$ & $9(11.0)$ & \\
\hline Strongly agree/Agree & $282(90.1)$ & $68(82.9)$ & \\
\hline The provider took a complete history of my problem. & & & 0.05 \\
\hline Strongly disagree/Disagree & $21(6.7)$ & $11(13.3)$ & \\
\hline Neither/No opinion & $47(15.0)$ & $17(20.5)$ & \\
\hline Strongly agree/Agree & $245(78.3)$ & $55(66.3)$ & \\
\hline The provider made my physical examination comfortable. & & & 0.09 \\
\hline Strongly disagree/Disagree & $18(5.7)$ & $6(7.2)$ & \\
\hline Neither/No opinion & $49(15.6)$ & $17(25.3)$ & \\
\hline Strongly agree/Agree & $247(78.7)$ & $56(67.5)$ & \\
\hline The provider prescribed appropriate tests and exams. & & & 0.35 \\
\hline Strongly disagree/Disagree & $18(5.7)$ & $5(6.0)$ & \\
\hline Neither/No opinion & $41(13.1)$ & $14(19.3)$ & \\
\hline Strongly agree/Agree & $255(81.2)$ & $62(74.7)$ & \\
\hline I believe the provider made a correct diagnosis for me. & & & 0.91 \\
\hline Strongly disagree/Disagree & $19(6.1)$ & $5(6.0)$ & \\
\hline Neither/No opinion & $43(13.8)$ & $13(15.7)$ & \\
\hline Strongly agree/Agree & $250(80.1)$ & $65(78.3)$ & \\
\hline
\end{tabular}

